\title{
Museum Websites of the First Wave: The rise of the virtual museum
}

\author{
Giuliano Gaia \\ InvisibleStudio Ltd \\ London, UK \\ giuliano.gaia@invisiblestudio.net
}

Jonathan $P$. Bowen

London South Bank University

London, UK

jonathan.bowen@lsbu.ac.uk

\author{
Stefania Boiano \\ InvisibleStudio Ltd \\ London, UK \\ stefania.boiano@invisiblestudio.net
}

University of Melbourne

Melbourne, Australia

aborda@unimelb.edu.au

\begin{abstract}
In this paper, we analyse trends of the first wave of museum websites (from the 1990s to the early 2000s) to understand how the characteristics of the Internet (specifically the World Wide Web), of museum staff, and museum audiences shaped the adoption of technology and new forms of participation and what they can tell us about engagement for museums of the future. The early development of online museum resources parallels the development of the EVA conference, which was establishing itself at a similar time.
\end{abstract}

Museum collections. Museum websites. Digital history. Digital preservation. Open source. Virtual museums.

\section{INTRODUCTION}

The first acknowledged website, The WWW Project (Berners-Lee et al. 1991a) was officially published online in 1991, but it is more challenging to trace the first museum website. Notwithstanding, it seems museums were reasonably quick to experiment with the Internet as a means of conveying visitor and collections information. Especially science and technology museums initiated an early presence online.

This first wave of online museums was also intrinsically associated with advances in web technologies, open source and open access, focusing on information systems (e.g., published databases) and hyperlinking content, comparable to the exploration of machine learning by museums of the present day. A seminal publication of the period, The Wired Museum (Jones-Garmil 1997), was already prescient in how technology might enable museums to accomplish interactions with content and audience engagement. But it also highlighted potential issues relevant today, such as content overload and lack of quality control.

In the same book (Jones-Garmil 1997), George MacDonald and Stephen Alsford provided insights into the future of digital information systems in museums based on their experience at the Canadian Museum of Civilisation. They speculated about the potential for the rise of the "MetaMuseum" - a museum that exists solely in cyberspace.

Within this context, the proposed paper aims to delve into this critical period of opportunity and adoption of a virtual presence and ways in which these pioneers became part of the mainstream and influenced museum website developments over the coming decades.

\section{EXAMPLES OF EARLY MUSEUM WEBSITES}

"It was fun to be experimenting with a new medium. I can still remember the feeling I had when I realized that our online audience exceeded our physical audience." (Rob Semper about the early years of the Exploratorium website).

The first World Wide Web site (still available under http://info.cern.ch/hypertext/WWW/TheProject.html) was published by Tim Berners-Lee on 6 August 1991 (Internet Live Stats 2020). We have to wait until 1995 to see a real web explosion; according to 
Internet Live Stats (2020), there were only 10 websites in 1992 and 130 in 1993; in 1994 the number reached 2,738 and 23,500 in 1995.

Understanding which the first museum website was is quite difficult. According to David Polly, creator with Rob Guralnick of the first version of the University of California Museum of Paleontology (UCMP), launched in August 1993 (Smith 2019).

\begin{abstract}
"As best as I remember, two museums beat us to the WWW: Honolulu Community College and the Smithsonian. HCC was not really a museum, but they put up a few nice pages about dinosaurs, and the Smithsonian simply converted their gopher picture server to HTML. I think Smithsonian did their gopher-to-web conversion before HCC came online. We were the first museum with extensive purposedesigned web exhibits." (Polly 2020).
\end{abstract}

After the UCMP came the Exploratorium of San Francisco (see Figure 1), as Rob Semper remembers (Semper 2020):

"When we launched our website on December 15, 1993, we could see about 600 websites (overall in the web). One was the UC Berkeley's Museum of Paleontology which had a site with some text and photos posted. One was the Library of Congress in Washington DC which was hosting an exhibit ROME REBORN: THE VATICAN LIBRARY \& RENAISSANCE CULTURE which had an online version. https://www.ibiblio.org/expo/vatican.exhibit/exhib it/About.html. We did not see any others."

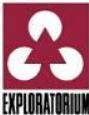

Welcome to the Exploratorium's World Wide Web server

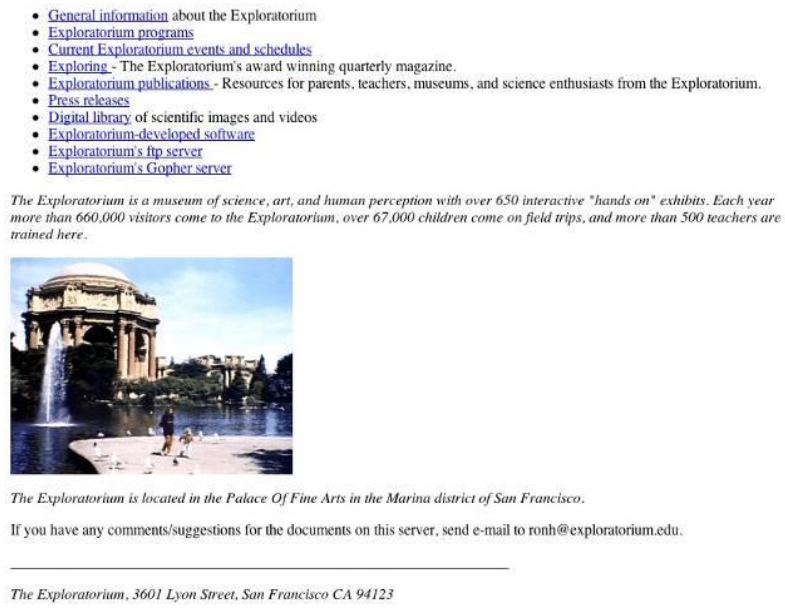

Figure 1: The home page of the Exploratorium website in April 1994 (courtesy Rob Semper).

In order to trace a better history of the first museum websites, we also conducted a brief research on the museum and technology resources of the time,
Museum Computer Network and Archives and Museum Informatics, both from the USA and often collaborating. The first mention of the WWW in Museum Computer Network conferences appear to be some sessions chaired by David Bridge (see Figure 2), a digital pioneer at the Smithsonian, who first introduced the upcoming Web and the new browser called Mosaic at the MCN/CIDOC conference in Washington, D.C. in 1994 (Samis 2020). We have found a brief report about the conference (Bearman 1994) mentioning the "Mosaic applications" of the University of California Museum of Paleontology.

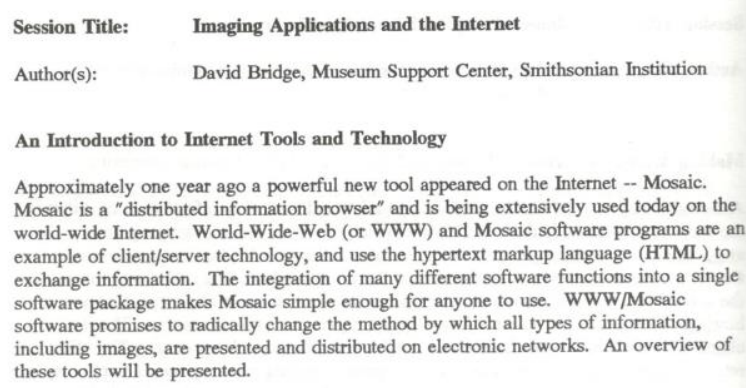

Figure 2: The presentation of one of the workshops by David Bridge at the 1994 MCN Conference (courtesy of Smithsonian Archives).

A note from Peter Samis of SFMOMA regarding the same sessions shows us all the interest that the new medium was beginning to foster in the museum community (Samis 2020):

\begin{abstract}
"There is a moment of palpable excitement in my notes from the MCN ' 94 Conference, held in the first days of September in Washington, D.C. Amidst reports on VR and VRML, MUDs, MOOs, and interactive databases, one session stands out in retrospect as being more equal than others: BIRTH OF THE WORLD WIDE WEB. David Bridge of the Smithsonian had the good fortune to be the emissary, announcing that as of November 1993, there was finally "a good client" for the client/server technology that had been developed by CERN in Switzerland: MOSAIC."
\end{abstract}

He concluded his announcement with an inclusive mandate meant to be an invitation (Samis 2020): "We're defining this medium-what works and what doesn't." In a word, stay tuned-and get involved!"

We think it is important to notice that the World Wide Web success was linked, in this first references, to the availability of a suitable browser, Mosaic, easy to install and use, working on Windows and capable of showing good quality images. It was the first browser able, in perspective, to open the web to the masses. It is significant, in our opinion, that the University of California Museum of Paleontology website was described a "Mosaic application" rather than a 
website at the $1994 \mathrm{MCN} / \mathrm{CIDOC}$ conference (Bearman 1994).

Science museums seem to have been at the head of the first web wave (Bowen et al. 2005), compared with, for example, art and history museums. According to Semper (2020):

"Part of the role of science museums is to present the ideas and the process of science and technology as well as authentic artifacts of science and therefore they are not so primally focused on the authentic and singular object like art museums. There was the early concern of rights ownership and reproductive authenticity in the art museum world. Also the science museum staff had technical backgrounds."

It is worth noting that the first museums to establish a web presence were both near the Silicon Valley a certain degree of osmosis can be expected between a thriving tech sector and the museums which are geographically near that area.

A notable exception to the "California-first" rule was the Smithsonian, which was quick in experimenting a web presence, for example with the Smithsonian Astrophysical Observatory website in 1993, and launched a comprehensive website for all its museums in 1995, in the presence of the then US Speaker of the House, Newt Gringrich. This was probably the first major launch of a museum website (Smithsonian 2020).

Bowen et al. (1998) write that the Natural History Museum in London was the first museum in the UK to have its own web server on the academic JANET network (due to the proximity of Imperial College London), launched in 1994. The London Science Museum followed shortly afterwards. The Museum of the History of Science in Oxford launched its website in 1995.

A paper of 1995, aptly titled Is Anybody Out There? (museums, audiences and the World Wide Web) (Gordon 1995) makes a very interesting read in order to get the challenges and opportunity felt by the staff facing with venturing on the WWW for the first time. In the paper Sue Gordon, the Information Systems Services Manager of National Museum of Science and Industry, recalls being asked in September 1994 to open a website. Gordon describes the challenges of implementing a website in a pre-Internet organization, but at the same time recognises the potential of the web for a museum, from e-commerce to video streaming.

The first museum websites suffered heavy technical limitations in terms of limited bandwidth, absence of HTML authoring tools and browser limitations; for example personalised content was not possible before the introduction of cookies by
Netscape, nor it was possible to design complex layouts before the invention of table-based web pages. Rob Semper recalls that on the Exploratorium website "We had to invent things as we went along including webcasting before video on the web was possible." (Semper 2020).

At the same time, the early web offered some good opportunities, due to the lack of competition. For example, it was easy to get good organic results on search engines: "We rode the Google organic search wagon which meant we did not need to develop a strong independent marketing enterprise, something that is imperative today." (Semper 2020). Opening a website soon became a good public-relations move; for example, the opening of the Science Museum of Milan website together with an Internet Lab for schools was featured on all Italian major newspapers in 1998.

\section{THE RISE OF THE "VIRTUAL MUSEUMS"}

Examining the papers of the first Museums and the Web conference held in Los Angeles in 1997 (http://www.museweb.net/bibliography/?by=1997), it can be noted that museums were enthusiastically embracing the new medium, opening "virtual museums" online, reaching towards schools and experimenting with online multimedia, for example using QuickTime Virtual Reality (QTVR) (Quackenbush et al. 1997).

The term "virtual" and "virtual museum" (Bowen 2000 ) is extensively used in the papers from that conference:

$$
\begin{aligned}
& \text { "Virtual Visitor Experience and Use." } \\
& \text { "The Virtual Library Museums Pages (VLmp): } \\
& \text { Whence and Whither?" (Bowen 1997b) } \\
& \text { "Building a Virtual Museum Community." } \\
& \text { "Virtual Museums: How to Make Digital } \\
& \text { Information Child-Friendly." } \\
& \text { "QuickTime Virtual Reality and Museums on the } \\
& \text { Internet." } \\
& \text { "Partners, Profiles, and the Public: Building a } \\
& \text { Virtual Museum Community." } \\
& \text { "Thinking Critically about Virtual Museums." }
\end{aligned}
$$

The concept of "virtual" was key of the digital development of those years, probably descending from the hype about the first wave of Virtual Reality applications of the late 1980s to the early 1990s. The WWW appeared as yet another way to "mirror" the physical reality in the digital world. The two realities appeared as different worlds in competition between themselves rather than a single, mixed 
reality as it is perceived today. We should bear in mind, though, that before the diffusion of the smartphone the mixing of real and digital dimensions of life was much more difficult (Bowen \& Giannini 2014)

Viewing the use of the term "virtual museums" in books using the Google Books Ngram Viewer (https://books.google.com/ngrams), we can see that the phrase started use around the birth of the web and peaked in 1998 (see Figure 3).

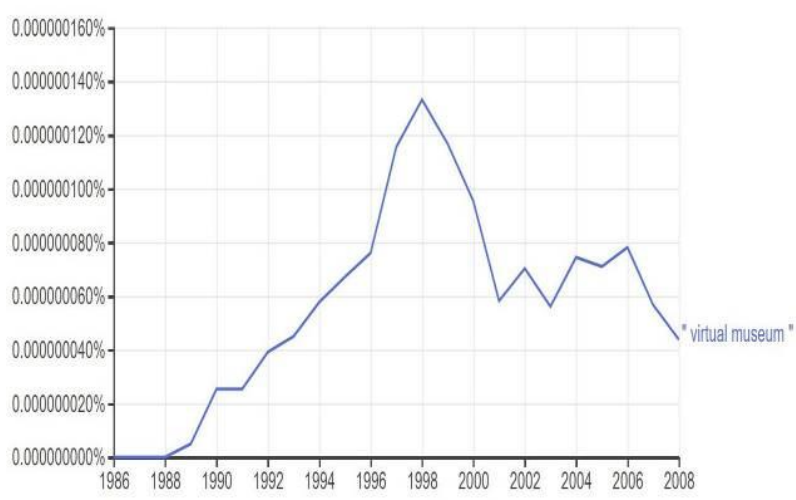

Figure 3: Use of the term "virtual museum" in books, 1988-2008 (Google Books Ngram Viewer).

Opening a museum website in the 1990s meant for an institution to face the conceptual problem of the virtual museum, as reported in this paper by Giuliano Gaia presented at the Museums and the Web conference (Gaia 1999):

"Like every Museum deciding to open a website, we found ourselves facing the dilemma "virtual visit or not?". This problem is quite well pointed out in a recent Italian publication (Forte et al. 1998), which can be summarized as follows:

There are three ways of making a virtual museum:

1. "simulated museum", trying to re-create the experience of visiting the actual museum (virtual tours, and so on...) without adding any information; according to this approach, to visit the museum or to visit the website should be the same.

2. "information": the website is an instrument to use before or after the visit; it offers a lot of information not available at the actual museum. According to the authors, this one is often the European way of thinking a web museum.

3. The real "virtual museum", a website in many parts independent from the actual museum, with many sections and exhibitions residing only on the net. This kind of virtual museum is not narrowly focused on the actual museum. This seems to be the American way of thinking.
At the Science Museum of Milan [see Figure 4[ we decided to put ourselves between the second and the third approach - we were not trying to simulate any real visit, but we wanted the website as an instrument to prepare and deepen the actual visit - while we had also some sections independent from the actual museum."

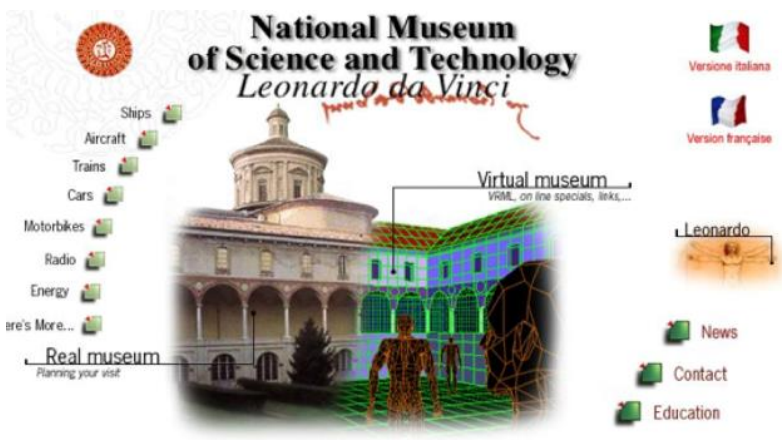

Figure 4: The 1999 home page of the Science Museum of Milan clearly shows the deep relationship between the "Real" and "Virtual" Museum.

This stress on the notion of virtuality partially explains why art museums were somewhat more hesitant in opening their websites. As noted previously by Rob Semper, the problem of image copyrights and "aura" are much more important for art museums than for other kinds of museums. This, coupled with a lack of technical staff, meant that many art museums waited to open their official websites, leaving a void on the web. This empty area was often occupied by single enthusiasts who created their own "virtual museums" publishing online images of the artworks without the museum consent or even knowledge. The most famous case is the Louvre, which was anticipated online in 1994 by a virtual museum called the "WebLouvre".

The WebLouvre was founded by the young French web developer Nicholas Pioch. Only in 1995 did the Louvre launch its official website (Renoux 2018; InvisibleStudio 2019) and insisted that Pioch remove the term "Louvre" from his website, so he changed the name from the WebLouvre to the WebMuseum, which is still available online today (https://www.ibiblio.org/wm/).

The creation of virtual museums highlights also the possibility for individuals to change the power relationship with the museum: for the first time, users could download and manipulate digital images of the artworks and be competitors of the museums in a media space. This was seen as terrifying by some museum professionals, but a great educational and cultural opportunity by others. For example, Witcomb (1997) described the new electronic age as an opportunity to end the equation Museum-Mausoleum and Walsh (1997) advocated: 


\begin{abstract}
"Using the interactive potentials of the web to change the one-way flow of information from art museum to visitor to a two-way flow which also moves from visitor to museum" [and] "Infusing the orientation towards constant change into the art museum so that the web helps the art museum to reinvent itself."
\end{abstract}

The concept of virtual museum survived through the evolution of the web; for example, the Google Arts\&Culture Project was born in 2011 as a way to "build a museum of museums" and empower users to create their own "virtual museums" (Sood 2011).

The growth of online museums in the 1990s was international and exponential as evidenced in the directory of the Virtual Library museums pages (VLmp), set up in 1994 (Bowen 1997a; 1997b). The VLmp was part of the WWW Virtual Library and supported by the International Council of Museums (ICOM). The directory was split by country, with individual maintainers for each country (Bowen 2002).

\section{VIRTUAL LIBRARY MUSEUMS PAGES}

This section discusses the development of the Virtual Library museums pages (VLmp) online directory of museums, initiated by Jonathan Bowen in 1994 as part of the WWW Virtual Library.

I first accessed the web through a Mosaic browser on a Sun workstation running the $X$ Window System (X11) at Oxford University in about 1993, linked to the Internet via the UK academic network JANET. At the time it was very slow to access American websites from Europe, with a transatlantic link from the United Kingdom of around $10 \mathrm{Mbps}$, the equivalent of a slow ethernet connection linking two continents. However, access speeds improved, especially for those of us at universities lucky enough not to have to use a modem and telephone line for online access, and it was enough to convince me to move from the SunOS operating system with no web browser to X-Windows.

I noticed a few museum-related websites such as information from the University of California Museum of Paleontology at UC Berkeley, set up in 1993 with support from Sun Microsystems (https://ucmp.berkeley.edu; Smith 2019). I also noticed the Virtual Library online, initiated by Tim Berners-Lee, Arthur Secret, and others to act as an early gateway directory for the web (http://www.vlib.org; Berners-Lee 1991b). At the time, it was very difficult to search the web without such a directory of links to web-based resources. Database searching of the web only really started with widespread use in 1995, with the advent of AltaVista, etc.
The WWW Virtual Library did not include a section on museums when I first viewed it and volunteers were encouraged to create Virtual Library sections on their own websites and request for these to be linked from the central WWW VL website. I was in the lucky position to have access to the webserver at the Oxford University Computing Laboratory, where I worked as a Research Officer at the time. Being at a university, I was also fortunate to have free rein in placing material online. So, in addition to material associated with my more official work in computer science, I also create a directory of links to online museum resources. On 16 June 1994, I sent an email to Arthur Secret at CERN with the URL for a web page at Oxford, offering to maintain the entry for "Museums" in the WWW Virtual Library (Bowen 2010).

On 10 March 1995, I published my first article concerning online museums in the Times Higher Education Supplement (Bowen 1995a). On 10 May 1995 , there was a highly significant early meeting about museums and the web entitled Museum Collections and the Information Superhighway, held at the Science Museum in London, and organised by the curator John Griffiths and others at the museum (see Figure 5). Most presentations were on future museum activities concerning the web, but I was able to present statistics on accesses to the "Virtual Library museums pages" (VLmp) at Oxford, which had already reached around a thousand accesses a day to the main page by this time (Bowen 1995b).

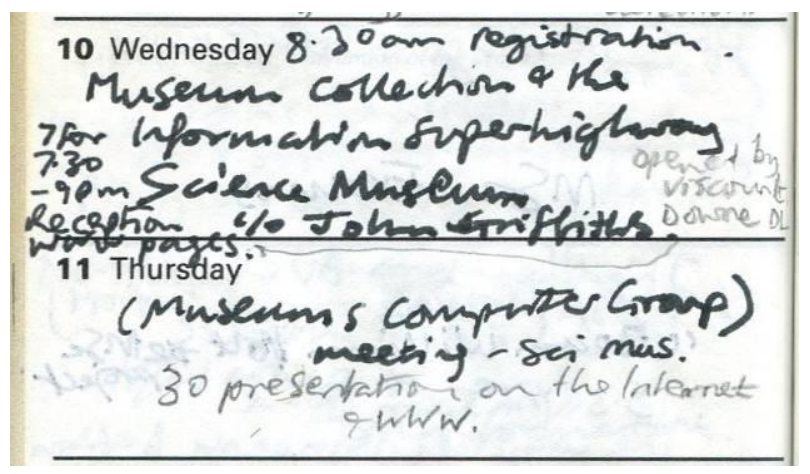

Figure 5: Diary entry for the Museum Collections and the Information Superhighway meeting followed by a

Museums Computer Group meeting on the Internet and the web, at the Science Museum, London, 10-11 May 1995 (courtesy Jonathan Bowen).

In June 1995, I decided to experiment with a purely online "virtual museum" and created a "Virtual Museum of Computing" (VMoC), which I incorporated to be part of VLmp (Bowen 1996b). The site's main page attracted a hundred hits a day within a week or so (Bowen 2010). It included various online "galleries", including a resource on the computing pioneer Alan Turing, curated by the 
Oxford-based mathematician and definitive Turing biographer, Andrew Hodges (Bowen et al. 2005).

On 27 July 1995, I presented my first paper at the EVA London conference, as part of a panel session moderated by Jim Hemsley, concerning VLmp, and published that October in a journal version (Bowen 1995c). Earlier I had contacted the Museums Journal with information on the exciting opportunities on the web for museums, but with no initial response. However, in August 1995, an article on VLmp appeared in the Museums Journal after the journal eventually contacted me (Bowen 1995d).

In 1996, the International Council of Museums (ICOM) adopted VLmp as its official online museums directory and hosted the resource on its own website (Bowen 1996a). Figure 6 shows the main VLmp page on the ICOM website in 1997 and Figure 7 show the same page in 2006.

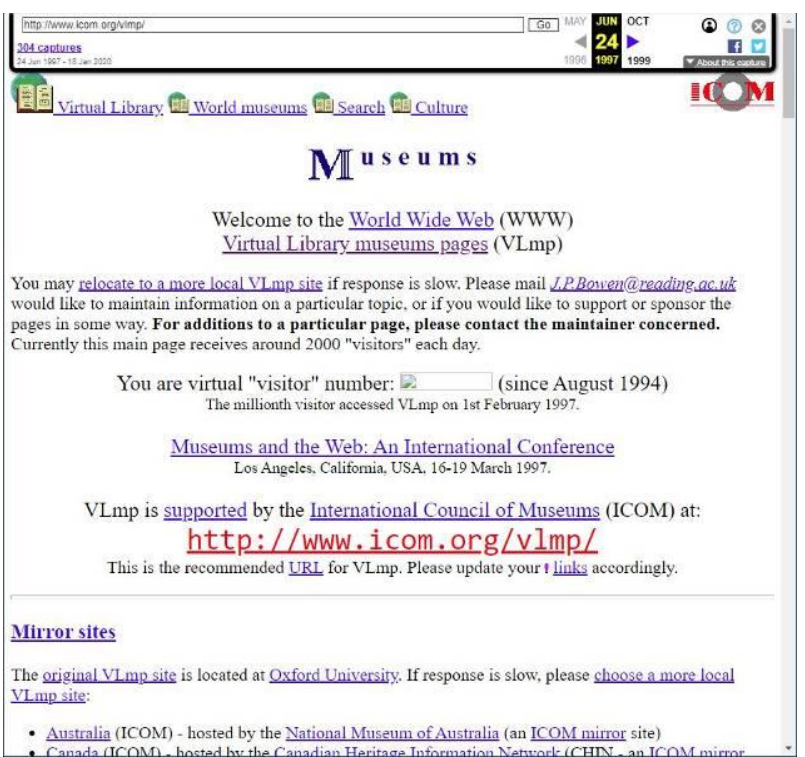

Figure 6: VLmp main page on the ICOM website in 1997. (Archived on Archive.org, 24 June 1997.)

Gradually the VLmp resource was mirrored at several sites around the world, including at the Canadian Heritage Information Network (CHIN). In addition, museum website lists for a number of individual countries were maintained by museum organizations and individuals, including first by CHIN in Canada. The United Kingdom list of museums was maintained by the Museums Documentation Association (MDA).

The countries with their own separately maintained entries can be seen in Figure 7. It is interesting to note both the countries and continents that were involved as well as those that were not involved. This is left as an exercise for the reader! At its height, about 20 people around the world were involved with the maintenance of VLmp.

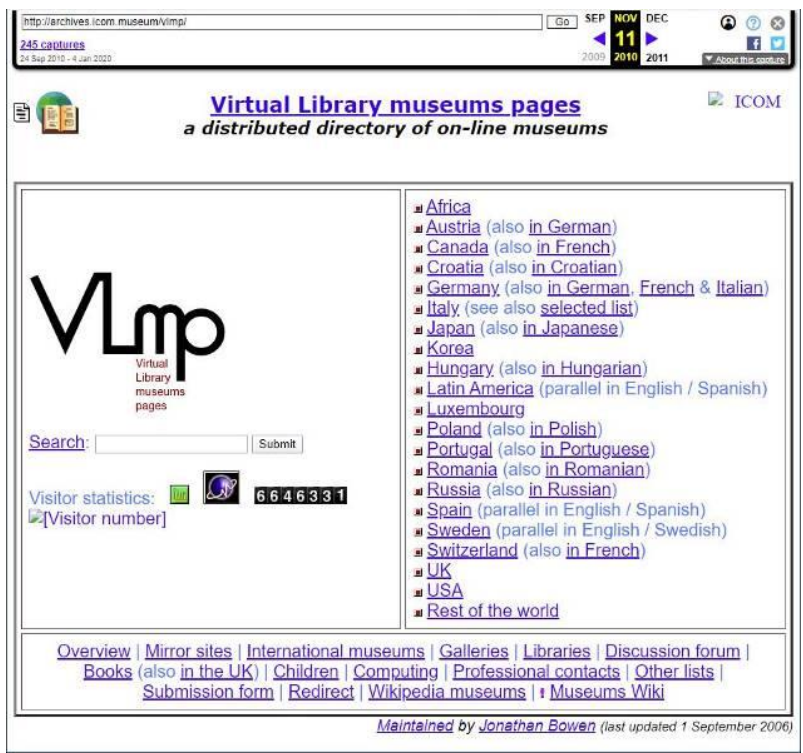

Figure 7: VLmp main page on the ICOM website in 2006. (Archived on Archive.org, 11 November 2010.)

In due course, the improvement in web searching facilities, especially through Google, and the improvement of other more general information sites, especially Wikipedia (Bowen and Angus 2006), made the VLmp and Virtual Library resource redundant, although VLmp still exists on a wiki site (https://museums.fandom.com).

\section{CONCLUSION}

By observing the first, pioneering museum websites a few considerations arise. The first one is that the browser technical features heavily influenced the shape and size of the earlier experimentations. The emergence of usable browser like Mosaic and Netscape was key in enlarging the web audience and the possibility for museums to embrace the web as a really promising medium. This means that museums should monitor emerging technologies, but only when those technologies become highly usable should a museum invest its limited resources on them.

The second consideration is that the professional conferences played an important part in spreading the knowledge of the web. Many of the protagonists got their first glimpse of the web from a workshop or a conference session, and published their first results in conferences, inspiring others to follow their footsteps. Even if today conferences suffer the competition of the online resources, their role in keeping museum professionals updated and inspired should not be downplayed.

The third consideration is about the enthusiasm with which the early adopters saw a new world opening in front of themselves. They could see the risks and challenges but were nonetheless thrilled 
by the exciting new opportunities opening in front of them, not only in technological terms but also as a way to change the general relationship between the museum and their visitors, as well as society in general. It would be very interesting to research if and how this change happened in practice, but this is beyond the scope of the present paper.

Finally, by observing how many papers were devoted to soon-to-be-dead technologies like CDROMs in the years soon after the web was invented, a question arises as to which new technologies are being developed that will shape our future. What is the next "big thing" around the corner that we are ignoring right now?

The authors hope that these observations on developments with respect to museums online, at a time when the EVA London and other conferences were establishing themselves, may help current developers in planning for the future, as museums become an increasing part of our "digital culture" (Giannini \& Bowen 2019).

\section{Acknowledgements}

Many thanks to Rob Semper, Peter Samis, Dave Polly, Rob Guralnick, Eric Longo, and Tad Bennicoff, for their kind help during the writing of this paper. Jonathan Bowen is grateful to Museophile Limited for funding. The web and the EVA conferences are around 30 years old and the authors are thankful for both in aiding and shaping their research.

\section{REFERENCES}

Bearman, D. (1994) CIDOC/MCN. Archives and Museum Informatics. 8(3), pp. 227-231 URL: http://www.archimuse.com/publishing/AMInewslette rs/AMInewsletter1994 8-3.pdf (retrieved 6 March 2020)

Berners-Lee, T., et al. (1991a) World Wide Web, CERN, Switzerland, 6 August. URL: http://info.cern.ch/hypertext/WWW/TheProject.html (retrieved 24 February 2020)

Berners-Lee, T., et al. (1991b) The WWW Virtual Library. URL: http://www.vlib.org (retrieved 1 March 2020)

Bowen, J. P. (1995a) Exhibitions in the ether. The Times Higher Education Supplement, Multimedia features, p. xii, 10 March.

Bowen, J. P. (1995b) The Virtual Library of museums. In G. Day (ed.), Proc. Museum Collections and the Information Superhighway, pp. 37-39. Science Museum, London, 10 May. URL: http://web.archive.org/web/19990120003322/www. nmsi.ac.uk/infosh/bowen.htm (retrieved 20 January 1999)
Bowen, J. P. (1995c) The World Wide Web Virtual Library of museums. Information Services \& Use, 15(4), pp. 317-324. DOI: 10.3233/ISU-1995-15408 Also in J. Hemsley (ed.), Proc. EVA'95: Electronic Imaging \& the Visual Arts, pp. 105-114. National Gallery, London, UK, 27 July.

Bowen, J. P. (1995d) Collections of collections. Museums Journal, 95 (8), pp. 24-25, August.

Bowen, J. P. (1996a) The Virtual Library museums pages on ICOM's World Wide Web site. ICOM News: Bulletin of the International Council of Museums, 49(2), p. 10.

Bowen, J. P. (1996b) Virtual Museum of Computing web site. IEEE Annals of the History of Computing, 18(4), p. 67.

Bowen, J. P. (1997a) The World Wide Web and the Virtual Library museums pages. European Review: Interdisciplinary Journal of the Academia Europaea, 5(1), pp. 89-104, January.

Bowen, J. P. (1997b) The Virtual Library museums pages (VLmp): Whence and whither? MW97: Museums and the Web 1997. URL: https://www. museumsandtheweb.com/biblio/the virtual library museums pages vlmp whence and whi.html (retrieved 7 March 2020)

Bowen, J. P. (2000) The virtual museum. Museum International, 52(1), pp. 4-7. DOI: 10.1111/1468$\underline{0033.00236}$

Bowen, J. P. (2002) Weaving the museum web: The Virtual Library museums pages. Program: Electronic Library and Information Systems, 36(4), pp. 236-252. DOI: $\underline{10.1108 / 00330330210447208}$

Bowen, J. P. (2010) A brief history of early museums online. The Rutherford Journal, 3. URL: http://www.rutherfordjournal.org/article030103.html (retrieved 1 March 2020)

Bowen, J. P. and Angus, J. (2006) Museums and Wikipedia. MW2006: Museums and the Web 2006. URL: https://www.museumsandtheweb.com/mw20 06/papers/bowen/bowen.html (retrieved 6 March 2020)

Bowen, J. P., Angus, J., Bennett, J., Borda, A., Hodges, A., Filippini-Fantoni, S. and Beler, A. (2005) The development of science museum Websites: Case Studies (Chapter XVIII). In T. W. Hin and R. Subramaniam (eds.), E-learning and Virtual Science Centers, Chapter XVIII, pp. 366392. Hershey, USA: Idea Group Publishing. DOI: 10.4018/978-1-59140-591-7.ch018

Bowen, J. P., Bennett, J., and Johnson, J. (1998) Virtual visits to virtual museums. MW98: Museums and the Web $1998 . \quad$ URL: https://www.museumsandtheweb.com/mw98/paper s/bowen/bowen paper.html (retrieved 8 January 2020) 
Bowen, J. P. and Giannini, T. (2014) Digitalism: The new realism? In $\mathrm{K}$. Ng, J. P. Bowen, and S. McDaid (eds.), EVA London 2014: Electronic Visualisation and the Arts. BCS, eWiC, pp. 324331. DOI: $\underline{10.14236 / \text { ewic/eva2014.38 }}$

Forte, M. and Franzoni, M. (1998) II museo virtuale: comunicazione e metafore., Sistemi Intelligenti, II Mulino, Bologna, anno X, n. 2, August. (In Italian.)

Gaia, G. (1999) Promoting a museum website on the net. MW99: Museums and the Web 1999. URL: https://www.museumsandtheweb.com/mw99/paper s/gaia/gaia.html (retrieved 6 March 2020)

Giannini, T. and Bowen, J. P. (eds.) (2019) Museums and Digital Culture: New perspectives and research. Series on Cultural Computing. Springer. DOI: $\underline{10.1007 / 978-3-319-97457-6}$

Gnatek, T. (2006) Taking the rough-and-tumble approach to science. The New York Times, 29 March. URL: https://www.nytimes.com/2006/03/29/ arts/artsspecial/taking-the-roughandtumbleapproach-to-science.html (retrieved 9 January 2020)

Internet Live Stats (2020) Total number of Websites. URL: https://www.internetlivestats.com/ total-number-of-websites/ (6 March 2020)

InvisibleStudio (2019) How old are those museum domains? Medium, 25 August. URL: https://med ium.com/@invisiblestudio/how-old-are-those-muse um-domains-50e344d226be (retrieved 24 February 2020)

Jones-Garmil, K. (1994) What will the Internet mean to museums, and what will museums mean to the Internet? Museum News, 73(4), pp. 33-59.

Jones-Garmil, K. (ed.) (1997) The Wired Museum: Emerging technology and changing paradigms. Washington, D.C.: American Association of Museum.

Polly, D. (2020) Email with the authors.
Quackenbush, A., Toomey, R. and Schroeder, E. (1997) QuickTime Virtual Reality and museums on the Internet. MW97: Museums and the Web 1997. URL: https://www.museumsandtheweb.com/biblio/ quicktime virtual reality and museums on the in ternet.html (6 March 2020)

Renoux A. (2018) Coordinating digital innovation in museums: The Louvre museum. Dedale, 19 June. URL: http://www.dedale.info/ objets/medias/autres/ am-renoux-louvre-berlinheritagesummit-2018-1136. pdf (retrieved 4 March 2020)

Samis P. (2020) Personal messages with the authors.

Semper R. (2020) Personal messages with the authors.

Smith, D. K. (2019) 25 years of the UCMP website. News \& Updates, UC Museum of Paleontology, USA. URL: https://ucmp.berkeley.edu/2019/02/25years-ucmp-website/ (retrieved 1 March 2020)

Smithsonian (2020) Web and Social Media Archiving. Smithsonian Institution Archives. URL: https://siarchives.si.edu/what-we-do/digital-curation /web-and-social-media-archiving (retrieved 4 March 2020)

Sood, A. (2011) Building a museum of museums on the web. Ted Talks. URL: https://www.ted.com/ talks/amit sood building a museum of museums on the web (retrieved 4 March 2020)

Walsh, P. (1997) The web and the unassailable voice. MW97: Museums and the Web 1997. URL: https://www.museumsandtheweb.com/mw97/speak /walsh.html (retrieved 7 March 2020)

Witcomb, A. (1997) The end of the mausoleum: Museums in the age of electronic communication. MW97: Museums and the Web 1997. URL: https://www.museumsandtheweb.com/mw97/speak /witcomb.html (retrieved 6 March 2020) 